\title{
German Catalysis Society Meeting: Exploring the Various Facets of Catalysis
}

\author{
Juliane Titus, ${ }^{[a]}$ Florian Harth, ${ }^{[a]}$ Rene Eckert, ${ }^{[b]}$ Bastian T. Mei, ${ }^{*[c]}$ and Tanja Franken ${ }^{[d]}$
}

\section{Tradition is Tradition}

Already for the $52^{\text {nd }}$ time the Annual Meeting of the German Catalysis Society (GeCatS) took place from March 13th to 15th, 2019. Following its long-standing tradition, the meeting was organized in the Neue Weimarhalle in the beautiful city of Weimar, Thuringia.

During the conference, the topics of discussions were manifold, ranging from heterogeneous to homogeneous, over molecular, bio-, electro- and photo-catalysis. Not only the catalytic applications, but also the theory behind the reactions, and the need for digitalization were in the scope of the Katalytikertagung 2019. Although the sun didn't help much to catalyze discussions, the Katalytikertagung provided the more than 500 participants plenty of opportunities to exchange knowledge, discuss scientific approaches and socialize with other enthusiastic peers. Even with the European Catalysis Conference taking place in Aachen in August 2019, the number of participants approached last year's attendance, which shows the importance of the Annual Meeting of the German Catalysis Society.

During the three days of the conference, 43 oral presentations were given, including four plenary lectures that gave deeper insights into their research. In addition to the large number of talks, 233 posters were shown during the two poster sessions. An exchange between scientists and also with 23 exhibitors who displayed their portfolio related to catalyst synthesis, characterization and catalytic experimentation was possible. As in the last years, two sessions were specifically organized by the YounGeCatS for young researchers, which included five poster workshops on Wednesday and the tradi-

[a] Dr. J. Titus, F. Harth

Institute of Chemical Technology

Universität Leipzig

Linnéstr. 3, Leipzig (Germany)

[b] Dr. R. Eckert

$R \& D$ Syngas Applications

Clariant Produkte (Deutschland) $\mathrm{GmbH}$

Waldheimer Str, 13, 83052 Bruckmühl/Heufeld (Germany)

[c] Dr. B. T. Mei

Photocatalytic Synthesis Group and

MESA + Institute for Nanotechnology

University of Twente

P.O. Box 217, 7500 AE Enschede (The Netherlands)

E-mail: b.t.mei@utwente.nl

[d] Dr. T. Franken

Forschungsbereich Prozesstechnik

ZHAW School of Engineering

Technikumstr. 9, 8400 Winterthur (Switzerland) tional session on Thursday afternoon. This year's topic was "Start-Ups in Catalysis".

\section{The Conference Catalysts 2019}

This year, the conference was kicked-off by the plenary lecture by Prof. Lutz Ackermann (Georg-August-Universität Göttingen). Professor Ackermann gave insights into the $\mathrm{C}-\mathrm{H}$ bond activation from late-stage peptide diversification to metal electrocatalysis. In this lecture, the versatility of $\mathrm{C}-\mathrm{H}$ activation was discussed using various examples with a focus on strategies to steer the selectivity of $\mathrm{C}-\mathrm{H}$ activation, including the regioselectivity of oxidative $\mathrm{C}-\mathrm{H}$ functionalization over $\mathrm{Ru}$ (II) complexes. Furthermore, selectivity trends in catalytic $\mathrm{C}-\mathrm{H}$ arylation and alkylation were discussed for a variety of transition metals ( $\mathrm{Mn}, \mathrm{Fe}, \mathrm{Co}, \mathrm{Ni}, \mathrm{Cu}$ ).

Following the plenary lecture, several talks showed the diversity of redox-catalysis and electrocatalysis. The poster contributions were the centerpiece of the first day's evening session. But before the poster party could close the first day of the conference with beer and pretzels, 25 young researchers had the chance to pitch their poster in one of five poster workshops, organized by YounGeCatS. As a result of the high quality of the contributions, longer discussions were required to select the winner of each poster workshop. The winners were rewarded with book prizes and gift bags, kindly sponsored by Swagelok Leipzig-Berlin. The winning contributors, announced during the GeCatS Party, were Jérôme Meyers, Tanja Bauer, Mathias Smialkowski, Oliver Schade and Niklas Stegmann.

\section{Swagelok}

The second day of the conference started with a plenary lecture by Prof. J.-D. Grunwaldt (KIT), who shared his latest research on "Tracking the active center in single-site and supported metal catalysts". Undoubtedly, understanding of the catalytic properties of a material requires characterization of solid catalysts under operating conditions. In-situ and operando characterization of supported metal catalysts allow researchers to track the catalyst's atomic structure and electronic state to explain changes of catalytic activity and thus provide valuable insight for further catalyst design. This lecture was the perfect 
introduction to the following four morning sessions dealing with In-Situ Characterization, Active Sites, Catalyst Preparation and Reaction Engineering, which were organized in two parallel sessions. During the lunch break, the second part of the poster party took place while the participants enjoyed a typical Thuringian sausage.

The plenary presentation of Prof. Deryn Fogg (University of Ottawa, Canada) on the "Frontiers in Olefin Metathesis" opened the afternoon. Although there academic impact of Ru catalyzed olefin metathesis is huge, the reaction has only rarely been applied in the production of drugs. This is mainly due to the fact that even commercially available catalysts, e.g. the famous Grubbs catalysts, were found unreliable under real process conditions, especially in the presence of water. Therefore, Prof. Fogg's lecture focused on the various degradation pathways of olefin metathesis catalysts and explained the audience how learning from the catalysts' weak spots can guide the development of new catalysts with improved applicability in drug production, which could eventually be also used in the upgrading of fatty acids via olefin metathesis. With that, the afternoon session had a fantastic start and leading to the sessions focusing on Acid-Base Catalysts, Molecular and Biocatalysts, Oligo-/Polymerization and Syngas. The lecture program ended in the early evening, and just before the GeCatS Party, YounGeCatS hosted a session with the goal to motivate and inspire the younger researchers among the participants. For the "Start-Ups in Catalysis" session two excellent speakers were invited to tell the interested audience about their practical experiences on how to spin-off a successfully growing company from a purely academic idea. In their appealing presentations, Thorsten Hornung, CEO and founder of Susteen, and Daniel Teichmann, CEO of Hydrogenious, talked about the advantages and drawbacks of independency, and also discussed the challenges they have faced to reach important milestones while keeping the company on track.

After the "Start-Ups in Catalysis", it was time to celebrate catalysis at the GeCatS Party with great live music, live cooking and the announcement of several prizes. The "Rote Löwe" was awarded to participants with 10 and 25 contributions to the Catalysis Society Meeting. From the large number of posters on display during the two poster parties, 8 contributions of young researchers were selected and honored. Apart from $M$. Smialkowski and N. Stegmann receiving their second award of the evening, M. Gerlach, R. Mom, A. Hüttner, T. Burger, H. Steldinger and S. Stadler received the poster awards. The most important prize of the evening, the Jochen Block-Prize, was awarded to Prof. Sandra Luber (University of Zurich, Switzerland). Professor Luber was honored for her excellent work in the field of theoretical chemistry. As clearly described in the laudatory speech by Prof. Matthias Driess, her work significantly contributed to the understanding of structure, dynamics, and spectroscopic fingerprints of catalytic materials. Finally the relaxing part of the evening started and the dance floor got crowded.

The last day of the conference started with the Jochen Block-Prize awardee lecture by Professor Luber with the title "Zooming-in on artificial water splitting by advanced ab initio

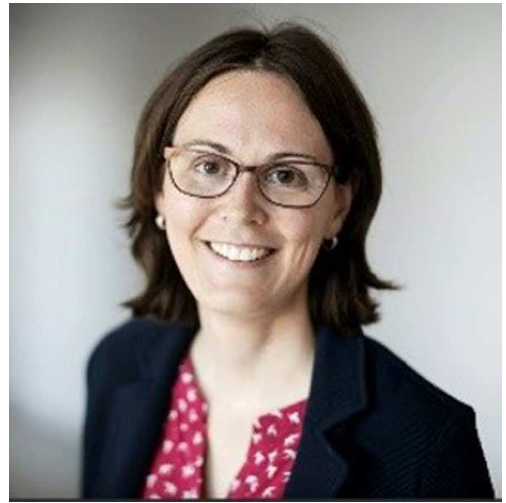

Figure 1. Jochen-Bloch-Prize awardee Prof. Sandra Luber, University of Zurich.

methods", which focused on the development of Co-based cubane-structured complexes. Inspired by the structure of photosystem II, her research on these promising and tunable model systems addresses the solar light-driven artificial water oxidation reaction - one of the bottlenecks in the overall water splitting reaction for sustainable hydrogen production. Using DFT calculations, plausible reaction pathways and the influence of different ligand environments were explored. To thoroughly understand the structure-activity relationship and dynamic effects, computational studies and spectroscopy were applied. Hence, Prof. Luber could impressively show why she was awarded the Jochen-Bloch Prize 2019.

The last two sessions of this Katalytikertreffen dealt with Theory and Data and Model Catalysts before Dr. Gerhard Mestl (Clariant) gave his plenary lecture with the title "Industrial Catalysis Research and Development: much more than just a recipe...". As the title already suggested, 2019's final plenary lecture portrayed the lengthy and intricate process of catalyst design through the eyes of an industrial chemist. Starting from a certain type of Mo-based mixed metal oxides (M1 phase), which are well-known suitable catalysts for selective oxidation, Dr. Mestl revealed the long way to bridge the gap from fundamental research to application. He focused on the optimization of catalyst composition and the processes operational window, but also emphasized crucial management aspects, e.g. assessment of the intellectual property situation, market developments, and how research projects are reviewed and recalibrated.

\section{Welcome back 2020}

During the conference, the diversity of catalysis was again revealed, and it was clear that the Katalytikertreffen continues to provide an excellent platform to connect researchers working in different disciplines in the field of catalysis. Brilliant plenary lectures, a great selection of oral contributions and the poster parties were the basis for scientific exchange, fruitful discussions and networking. In 2020, the German Catalysis Society 
Meeting will take place on March $11^{\text {th }}-13^{\text {th }}$ in Weimar, a city rich of (catalysis) tradition. See you next year!

\section{The Young German Catalysis Society}

It is the ambition of YounGeCatS to connect all interested young researchers in the field of catalysis by strengthening the exchange between academia and industry. In addition to events where the members of YounGeCatS can meet in person, like the Start-Up session or the casual get-together on the first evening of the Katalytikertreffen, YounGeCatS would like to invite you to follow us on Linkedln. By following us online, we will keep you updated about travel grants and our future events such as the annual network meeting, summer school contributions, and sessions at the Katalytikertagung, as well as about other interesting events organized by our international colleagues.



